\title{
Preventive Effects of a Kampo Medicine, Shosaikoto, on Inflammatory Responses in LPS-Treated Human Gingival Fibroblasts
}

\author{
Toshiaki Ara,${ }^{a, b}$ Yoshihiro MaedA, ${ }^{b}$ Yoshiaki FuJINAmi, ${ }^{a}$ Yasuhiro Imamura, ${ }^{a, b}$ \\ Toshimi HATTORI, ${ }^{a, b}$ and Pao-Li WANG ${ }^{*, a, b}$ \\ ${ }^{a}$ Department of Pharmacology, Matsumoto Dental University; and ${ }^{b}$ Department of Hard Tissue Research, Graduate \\ School of Oral Medicine, Matsumoto Dental University; 1780 Gobara, Hirooka, Shiojiri, Nagano 399-0781, Japan. \\ Received December 20, 2007; accepted February 16, 2008; published online March 7, 2008
}

In the present study, we investigated the anti-inflammatory effects of a Kampo medicine Shosaikoto (TJ-9) using in vitro periodontal disease model, in which human gingival fibroblasts (HGFs) treated with lipopolysaccharide (LPS) from Porphyromonas gingivalis (PgLPS) produce IL-6, IL-8 and prostaglandin $\mathrm{E}_{2}\left(\mathrm{PGE}_{2}\right)$. Treatment with PgLPS (10 ng/ml), TJ-9 (up to $1 \mathrm{mg} / \mathrm{ml}$ ) and their combinations for $24 \mathrm{~h}$ did not affect the viability of HGFs. Moreover, TJ-9 did not alter LPS-induced IL-6 and IL-8 productions. However, TJ-9 significantly suppressed LPS-induced PGE $_{2}$ production in a dose-dependent manner but TJ-9 alone did not affect basal PGE level. Western blotting demonstrated that TJ-9 decreased cyclooxygenase-2 (COX-2) expression in a dosedependent manner but not phospholipase $A_{2}$. Moreover, TJ-9 selectively and dose-dependently inhibited COX-2 activity. These results suggest that TJ-9 decreased PGE $_{2}$ production by inhibition of both COX-2 expression and activity and that TJ-9 may be useful to improve gingival inflammation in periodontal disease.

Key words Shosaikoto; periodontal disease; gingival fibroblast; lipopolysaccharide

Periodontal disease is one of major oral diseases and is thought to be biofilm infectious disease. ${ }^{1)}$ Periodontal disease comprises a group of infections that leads to inflammation of the gingiva and destruction of periodontal tissues, and is accompanied by alveolar bone loss in severe clinical cases. The tissue destruction is the result of activation of the host's immuno-inflammatory response to virulence factors ${ }^{2)}$ such as lipopolysaccharide (LPS) and peptidoglycan. The elimination of these virulence factors by initial preparation is very important for the treatment of periodontal disease. In some case, non-steroidal anti-inflammatory drugs (NSAIDs) were administrated to improve gingival inflammation. In fact, many studies demonstrated that systemic administration of acid NSAIDs prevents gingival inflammation and alveolar bone resorption in animals and humans (summarized in ref. 2). However, acid NSAIDs are reported to have side effects such as gastrointestinal dysfunction.

Shosaikoto (TJ-9) is one of the Kampo medicines and has been used clinically to treat various inflammatory diseases including chronic hepatitis. In addition, TJ-9 protects the liver plasma membrane in endotoxin-treated mice. ${ }^{3)}$ TJ-9 inhibits LPS-induced tumor necrosis factor (TNF)- $\alpha$ production by macrophages ${ }^{4)}$ and pretreatment with TJ-9 prevents septic shock in LPS-injected rats. ${ }^{5)}$ TJ-9 also inhibits prostaglandin $\mathrm{E}_{2}\left(\mathrm{PGE}_{2}\right)$ production by zymosan-treated monocytes. ${ }^{6}$ Moreover, TJ-9 suppresses liver inflammatory responses and fibrosis in dimethylnitrosamine-induced liver injury rats. ${ }^{7)}$ And, TJ-9 induces apoptosis of a human hepatocellular carcinoma cell line and a cholangiocarcinoma cell line, ${ }^{8)}$ and prevents the development of hepatocellular carcinoma. ${ }^{9)}$ Considering these reports, we assumed that TJ-9 has an ability to suppress gingival inflammation in periodontal disease.

Human gingival fibroblasts (HGFs) are the most prominent cells in periodontal tissue. And HGFs produce inflammatory cytokines such as interleukin (IL)-6 and IL-8 and eicosanoids such as $\mathrm{PGE}_{2}$ when HGFs were treated with
LPS. $^{10-12)}$ Therefore, we regard this experimental system, in which HGFs were treated with LPS, as in vitro periodontal disease model. Moreover, because HGFs sustain to produce IL-6 and IL- 8 in the presence of LPS, ${ }^{13)}$ we consider that the examinations of effect on HGFs, as well as monocytes and macrophages, are important in the study on periodontal disease. In the present study, we examined anti-inflammatory effects of TJ-9 in this model using HGFs.

\section{MATERIALS AND METHODS}

Reagents Shosaikoto (TJ-9) was obtained from Tsumura \& Co. (Tokyo, Japan). TJ-9 was suspended in Dulbecco's modified Eagle's medium (D-MEM, Sigma, St. Louis, MO, U.S.A.) containing $10 \%$ heat-inactivated fetal calf serum, 100 units $/ \mathrm{ml} \mathrm{penicillin} \mathrm{and} 100 \mathrm{mg} / \mathrm{ml}$ streptomycin (culture medium) and was rotated at $4{ }^{\circ} \mathrm{C}$ overnight. Then, the suspension was centrifuged and the supernatant was filtrated through $0.45 \mu \mathrm{m}$-pore membrane. Porphyromonas gingivalis LPS (PgLPS) was provided by Drs. Tatsuji Nishihara and Nobuhiro Hanada (National Institutes of Public Health, Wako, Japan). The antibodies against cytoplasmic phospholipase $\mathrm{A}_{2}$ (cPLA ${ }_{2}$, sc-438), cyclooxygenase-2 (COX-2, sc1745) and actin (sc-1616) were purchased from Santa Cruz Biotechnology (Santa Cruz, CA, U.S.A.). Horseradish peroxidase-conjugated secondary antibodies were from Jackson ImmunoResearch Laboratories (West Grove, PA, U.S.A.).

Cells HGFs were prepared from explants of human normal gingival tissues as described previously, ${ }^{14)}$ and were maintained in culture medium in a humidified atmosphere of $5 \% \mathrm{CO}_{2}$ at $37^{\circ} \mathrm{C}$. HGFs were used between 10th to 20th passages in the assays. The present study was approved by the Ethical Committee of our institution. Informed consent was obtained from each subject.

MTT Assay The numbers of cells were measured by MTT assay. In brief, the media were removed by aspiration and the cells were treated with $0.5 \mathrm{mg} / \mathrm{ml}$ dimethylthiazol-2- 
yl-2,5-diphenyltetrazolium bromide (MTT, Sigma) in culture medium for $4 \mathrm{~h}$ at $37^{\circ} \mathrm{C}$. After washed with PBS once, isopropanol $/ 0.04 \mathrm{M} \mathrm{HCl}$ was added and $\mathrm{OD}_{570}$ were measured and the value of blank is subtracted.

Cytokine Measurement by Enzyme-Linked Immunosorbent Assay (ELISA) HGFs $\left(1 \times 10^{4}\right.$ cells/well $)$ were seeded in 96-well plates and incubated in serum-containing medium at $37^{\circ} \mathrm{C}$ overnight. Then, the cells were treated with various concentrations of TJ-9 $(0$ to $1 \mathrm{mg} / \mathrm{ml})$ in the absence or presence of PgLPS $(10 \mathrm{ng} / \mathrm{ml})$ for $24 \mathrm{~h}$ (200 $\mu \mathrm{l}$ per each well). The numbers of cells were measured using MTT assay. The concentrations of IL-6, IL-8 and prostaglandin $\mathrm{E}_{2}\left(\mathrm{PGE}_{2}\right)$ in the culture supernatants were measured by ELISA according to the manufactures' instructions (IL-6 and IL-8, Biosource International Inc., Camarillo, CA; $\mathrm{PGE}_{2}$, R\&D Systems, Minneapolis, MN, U.S.A.), and were adjusted by the number of remaining cells.

Western Blotting HGFs were cultured in $60 \mathrm{~mm}$ dish and treated with the combinations of LPS and TJ-9. After $24 \mathrm{~h}$, cells were washed twice with PBS, transferred into microcentrifuge tubes, and centrifuged at $6000 \times \boldsymbol{g}$ for $5 \mathrm{~min}$ at $4{ }^{\circ} \mathrm{C}$. Supernatants were aspirated and cell were lysed on ice in lysis buffer $(50 \mathrm{~mm}$ Tris- $\mathrm{HCl}, \mathrm{pH} 7.4,1 \%$ Nonidet P-40, $0.25 \%$ sodium deoxycholate, $150 \mathrm{~mm} \mathrm{NaCl}, 1 \mathrm{~mm}$ EGTA, $1 \mathrm{~mm}$ sodium orthovanadate, $10 \mathrm{~mm} \mathrm{NaF}, 1 \mathrm{~mm}$ phenylmethylsulfonyl fluoride (PMSF), $10 \mu \mathrm{g} / \mathrm{ml}$ aprotinin, $5 \mu \mathrm{g} / \mathrm{ml}$ leupeptin and $1 \mu \mathrm{g} / \mathrm{ml}$ pepstatin) for $30 \mathrm{~min}$ at $4^{\circ} \mathrm{C}$. Then, samples were centrifuged at $12000 \times \boldsymbol{g}$ for $15 \mathrm{~min}$ at $4{ }^{\circ} \mathrm{C}$ and supernatants were collected. The protein concentration was measured using BCA Protein Assay Reagent kit (Pierce Chemical Co., Rockford, IL, U.S.A.).

The samples ( $10 \mu \mathrm{g}$ proteins) were fractionated in polyacrylamide gel under reducing conditions and transferred onto polyvinylidene difluoride (PVDF) membrane (Hybond$\mathrm{P}$, Amersham Bioscience, Uppsala, Sweden). The membranes were blocked with 5\% ovalbumin (Nacalai Tesque, Kyoto, Japan) for $1 \mathrm{~h}$ at room temperature and incubated with primary antibody for additional $1 \mathrm{~h}$. The membranes were further incubated with horseradish peroxidase-conjugated secondary antibodies for $1 \mathrm{~h}$ at room temperature. Protein bands were visualized with ECL kit (Amersham Bioscience).

Measurement of Cyclooxygenase Activity The effects of TJ-9 on the activities of COX-1 and COX-2 were analyzed using COX inhibitor screening assay (Cayman Chemical, Ann Anbor, MI, U.S.A.) according to the manufactures' instructions. COXs activities were evaluated by the measurement of prostaglandin produced from arachidonic acid by COX-1 or COX-2 in duplicate. These values were normalized to a relative value of $100 \%$ for the cells without both PgLPS and TJ-9 treatment.

Statistical Analysis Data are presented as means \pm standard deviation (S.D.). Differences between groups were evaluated using the pairwise comparison test corrected with Holm method (Fig. 2). Differences between control group and test groups were evaluated with Dunnett method (Fig. 3). All computations were performed with the statistical program R (http://www.r-project.org/). Values with $p<0.05$ were considered as significantly different.

\section{RESULTS}

The Effects of TJ-9 on IL-6, IL-8 and PGE 2 Productions We examined the effects of TJ-9 in in vitro periodontal disease model. TJ-9 was used at 0 to $1 \mathrm{mg} / \mathrm{ml}$ because the numbers of HGFs were not decreased at least up to $2 \mathrm{mg} / \mathrm{ml}$ after $24 \mathrm{~h}$ but decreased at $5 \mathrm{mg} / \mathrm{ml}$ (data not shown). First, we examined whether LPS affects viability of HGFs in various concentrations of TJ-9 by MTT assay. No obvious difference was observed in the cell numbers (Fig. 1).

Next, we examined whether TJ-9 affects the productions of inflammatory cytokines (IL-6 and IL-8) and PGE $_{2}$ by HGFs. The concentrations of IL-6, IL- 8 and PGE 2 were adjusted by the results of MTT assay (Fig. 1). In the absence of PgLPS, TJ-9 did not affect IL-6 and IL-8 production (Figs. 2A, B). When HGFs were treated with $10 \mathrm{ng} / \mathrm{ml}$ of PgLPS, HGFs produced large amount of IL- 6 and IL-8. TJ-9 did not affected LPS-induced IL-6 and IL-8 productions (Figs. 2A, B).

HGFs without any treatment produced low level of $\mathrm{PGE}_{2}$. When HGFs were treated with PgLPS, HGFs produced significant level of $\mathrm{PGE}_{2}$. TJ-9 inhibited LPS-induced $\mathrm{PGE}_{2}$ production in a dose-dependent manner (Fig. 2C). However, TJ-9 had little effect on $\mathrm{PGE}_{2}$ production in the absence of PgLPS. The similar results were found for $\mathrm{PGE}_{2}$ production when HGFs were treated with LPS (data not shown). These results indicated that TJ-9 inhibited LPS-induced production PGE $_{2}$ by HGFs but not IL-6 and IL-8.

The Effects of TJ-9 on COX-2 Expression and Activity HGFs were treated with $10 \mathrm{ng} / \mathrm{ml}$ of PgLPS for 0 (untreated), 4,8 and $24 \mathrm{~h}$, and protein levels of $\mathrm{CPLA}_{2}$ and COX-2 were examined by Western blotting. cPLA ${ }_{2}$ was expressed at 4 and $8 \mathrm{~h}$ and COX-2 at $8 \mathrm{~h}$ (data not shown). Therefore, we examined the effects of TJ-9 on LPS-induced cPLA $_{2}$ and COX-2 expressions at $8 \mathrm{~h}$. The levels of $\mathrm{CPLA}_{2}$ were similar regardless of PgLPS and TJ-9. COX-2 was not detected in the absence of PgLPS, and induced by PgLPS treatment. LPS-induced COX-2 expression was decreased with TJ-9 in a dosedependent manner (Fig. 3A).

We also examined whether TJ-9 inhibits COX-1 and COX2 activities. Up to $1 \mathrm{mg} / \mathrm{ml}$ of TJ-9 did not affected COX-1 activity. TJ-9 did not affected COX-2 activity at $0.1 \mathrm{mg} / \mathrm{ml}$ but did at 0.3 and $1 \mathrm{mg} / \mathrm{ml}$ (Fig. 3B). These results indicate that TJ-9 selectively inhibited COX-2 activity and that suggested that $\mathrm{TJ}-9$ decreases $\mathrm{PGE}_{2}$ production by the inhibition

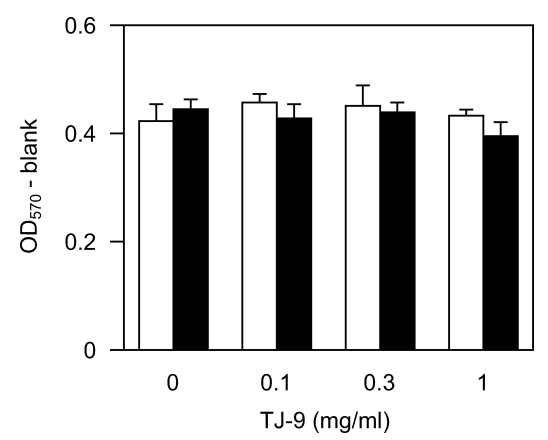

Fig. 1. The Effect of Shosaikoto (TJ-9) on Viability of HGFs

HGFs were treated with the combinations with PgLPS $(10 \mathrm{ng} / \mathrm{ml})$ and TJ-9 (0 to $1 \mathrm{mg} / \mathrm{ml}$ ) for $24 \mathrm{~h}$ and were performed to MTT assay. Open bars, treatment without PgLPS; closed bars, treatment with $10 \mathrm{ng} / \mathrm{ml}$ of PgLPS. 
A

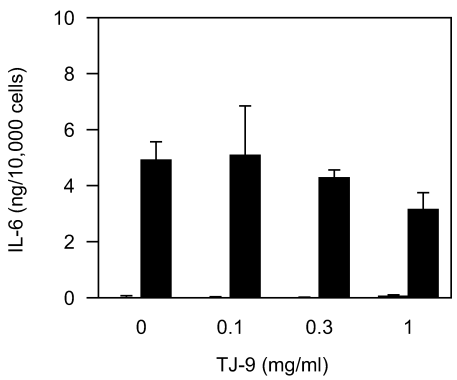

B

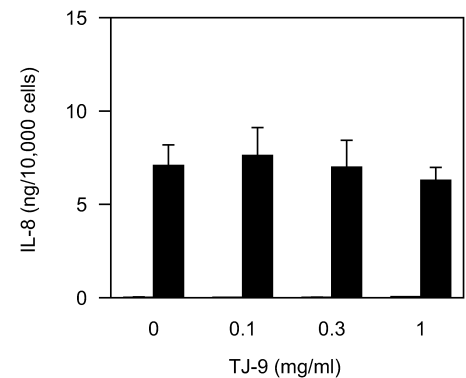

C

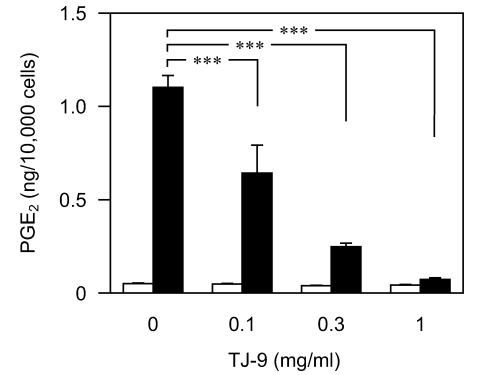

A

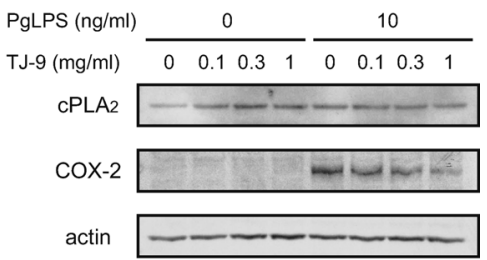

B
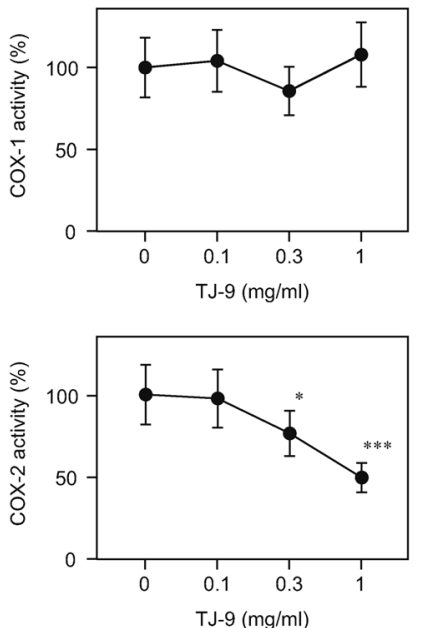

Fig. 3. (A) The Effects of Shosaikoto (TJ-9) on $\mathrm{cPLA}_{2}$ and COX-2 Expressions

HGFs were treated with the combination of PgLPS and TJ-9 for $8 \mathrm{~h}$, and protein levels were examined by Western blotting.

(B) The Effects of TJ-9 on COXs Activity

$* p<0.05$ and $* * * p<0.001$ vs. control by Dunnett method.

Fig. 2. The Effects of Shosaikoto (TJ-9) on the Production of IL-6, IL-8 and $\mathrm{PGE}_{2}$

HGFs were treated with the combinations with PgLPS $(10 \mathrm{ng} / \mathrm{ml})$ and TJ-9 (0 to $1 \mathrm{mg} / \mathrm{ml}$ ) for $24 \mathrm{~h}$, and the concentrations of IL-6 (A), IL-8 (B) and $\mathrm{PGE}_{2}$ (C) were measured by ELISA. The concentrations were adjusted by the cell numbers and expressed as per 10000 cells. $* * * p<0.001 v s$. control corrected by Holm method ( 7 nul hypotheses). Open bars, treatment without PgLPS; closed bars, treatment with $10 \mathrm{ng} / \mathrm{ml}$ of PgLPS.

of both COX-2 expression and activity.

\section{DISCUSSION}

In the present study, we examined anti-inflammatory effects of TJ-9 in in vitro periodontal disease model. We showed that TJ-9 suppressed LPS-induced $\mathrm{PGE}_{2}$ production by HGFs as well as by zymosan-treated monocytes. ${ }^{6}$ Therefore, we consider that TJ-9 has anti-inflammatory effects in periodontal disease as well as other inflammatory diseases.

Many various factors such as inflammatory cytokines and chemical mediators are known to be involved in inflammatory responses. In the present study, we examined the productions of IL-6, IL-8 and $\mathrm{PGE}_{2}$ as the index of inflammatory response. IL-6 has an ability to induce osteoclastogenesis $^{15)}$ and IL-8 acts as a chemoattractant for neutrophils (reviewed in ref. 16). Therefore, these cytokines are closely associated with onset of periodontal disease. In addition, it is widely known that $\mathrm{PGE}_{2}$ leads to inflammatory responses such as vasodilation, enhanced vascular permeability and pain generation. In the present study, we demonstrated that

TJ-9 suppresses LPS-induced $\mathrm{PGE}_{2}$ production to basal level (Fig. 2C) but did not affect IL-6 and IL-8 productions (Figs. 2A, B).

$\mathrm{PGE}_{2}$ is produced from phospholipids of cytoplasmic membranes through arachidonic acid cascade. Arachidonic acid released from membrane phospholipids by $\mathrm{PLA}_{2}$ is converted into $\mathrm{PGH}_{2}$ by $\mathrm{COX}-1$ and $\mathrm{COX}-2$, and finally into $\mathrm{PGE}_{2}$. In the present study, TJ-9 suppressed both COX-2 expression and its activity, leading to decreased $\mathrm{PGE}_{2}$ production, while TJ-9 did not alter $\mathrm{CPLA}_{2}$ expression nor inhibit COX-1 activity (Fig. 3). These results reflect the fact that TJ9 did not affect basal $\mathrm{PGE}_{2}$ production in the absence of LPS (Fig. 2C). From these results, it is suggested that TJ-9 has some components which inhibit COX-2 selectively.

TJ-9 contains several flavonoids such as baicalein, baicalin and wogonin. ${ }^{17)}$ In particular, baicalein (but not baicalin) ${ }^{18)}$ and wogonin ${ }^{19)}$ are reported to suppress COX-2 expression in LPS-treated mouse macrophage. Moreover, wogonin suppresses COX-2 expression in mouse skin fibroblasts treated with tetradeanoyl phorbol acetate (TPA), IL-1 $\beta$ or TNF- $\alpha{ }^{20)}$ Therefore, it is suggested that at least baicalein and wogonin suppress COX-2 express in LPS-treated HGFs (Fig. 3A). In addition, TJ-9 includes steroidal compound such as saikosaponins. Saikosaponins have a steroidal structure and show anti-inflammatory effects. ${ }^{21)}$ However, these steroidal components may be unlikely because, if so, the expression of $\mathrm{PLA}_{2}$ as well as COX-2 may be suppressed.

The reason that TJ-9 suppresses COX-2 expression but not 
IL-6 and IL- 8 expression may be due to the difference in transcriptional regulation in promoter region. Baicalein inhibits CCAAT/enhancer binding protein $\beta(\mathrm{C} / \mathrm{EBP} \beta)$ DNAbinding activity in COX-2 promoter region and suppresses COX-2 expression in mouse macrophages, ${ }^{18)}$ while $\mathrm{C} / \mathrm{EBP} \beta$ plays no or little role in IL-6 and IL- 8 transcription in LPStreated dermal fibroblasts and LPS-treated rheumatoid arthritis synovial fibroblasts. ${ }^{22)}$

Taken together, our results suggest that the mechanism of anti-inflammatory effects of TJ-9 is mainly the suppression of $\mathrm{PGE}_{2}$ production rather than those of inflammatory cytokines. Moreover, this decreased $\mathrm{PGE}_{2}$ production will cause substantial reduction of $\mathrm{PGE}_{2}$ in periodontal tissue because periodontal tissue is mainly occupied by HGFs.

Many studies demonstrated that NSAIDs administration prevents gingival inflammation (summarized in ref. 2). And several clinical studies indicated that the concentration of $\mathrm{PGE}_{2}$ in gingival crevicular fluid (GCF) is increased in periodontal disease ${ }^{23)}$ and is decreased by the administration of NSAIDs such as oral administration with flurbiprofen ${ }^{24)}$ and mouse wash with ketrolac. ${ }^{25)}$ Considering the facts that both NSAIDs and TJ-9 suppress $\mathrm{PGE}_{2}$ production, it is possible that administration of $\mathrm{TJ}-9$ also decreases $\mathrm{PGE}_{2}$ concentration in GCF and results in the improvement of gingival inflammation. Therefore, TJ-9 may be useful for the improvement of gingival inflammation in periodontal disease. Importantly, TJ-9 inhibits only COX-2 activity (Fig. 3B), while acid NSAIDs inhibit both COX-1 and COX-2 activities. Because $\mathrm{PGE}_{2}$ produced by $\mathrm{COX}-1$ protects gastric mucosa, these results suggest that TJ-9 may have minimal gastrointestinal dysfunction. Although COX-2 selective inhibitors are used to avoid gastrointestinal dysfunction, recent studies revealed that COX-2 selective inhibitors increase the risk of arthetothrombosis $^{26)}$ and ischemic stroke. ${ }^{27)}$ Therefore, TJ-9 may show the similar side effects as COX-2 selective inhibitors. However, the ischemic stroke risk is thought to be by additional pharmacological properties other than COX-2 inhibition because not all COX-2 selective inhibitors show the risk (e.g. the risk of rofecoxib is significantly high than control but that of celecoxib is not significant). ${ }^{27}$ Moreover, the ability of TJ-9 to selectively inhibit COX-2 may lead to these disorders at very low risk because the occurrence of these disorders by TJ-9 administration has not been reported. Taking into consideration these findings, although the investigation is needed whether TJ-9 has the risk of these disorders, TJ-9 may be useful for the improvement of inflammation in periodontal disease.

Acknowledgments We thank Drs. Tatsuji Nishihara and Nobuhiro Hanada (National Institutes of Public Health) for providing $P$. gingivalis LPS. We also thank Associate Prof. Takashi Uematsu (Department of Oral and Maxillofacial Surgery) for HGFs preparation and Keiko Fujii for technical assistance. The study was supported in part by a Grant-inAid for Scientific Research from Japan Society for the Pro- motion of Science (Code No. 19592419). We declare that there is no conflict of interest.

\section{REFERENCES}

1) Costerton J. W., Stewart P. S., Greenberg E. P., Science, 284, 13181322 (1999).

2) Salvi G. E., Lang N. P., J. Clin. Periodontol., 32 (Suppl. 6), 108-129 (2005).

3) Sakaguchi S., Tsutsumi E., Yokota K., Biol. Pharm. Bull., 16, 782786 (1993).

4) Sakaguchi S., Furusawa S., Biol. Pharm. Bull., 27, 1468-1470 (2004).

5) Sakaguchi S., Furusawa S., Iizuka Y., Biol. Pharm. Bull., 28, 165 168 (2005).

6) Miyamoto K., Lange M., McKinley G., Stavropoulos C., Moriya S., Matsumoto H., Inada Y., Am. J. Chin. Med., 24, 1-10 (1996).

7) Kusunose M., Qiu B., Cui T., Hamada A., Yoshioka S., Ono M., Miyamura M., Kyotani S., Nishioka Y., Biol. Pharm. Bull., 25, 1417-1421 (2002).

8) Yano H., Mizoguchi A., Fukuda K., Haramaki M., Ogasawara S., Momosaki S., Kojiro M., Cancer Res., 54, 448 - 454 (1994).

9) Oka H., Yamamoto S., Kuroki T., Harihara S., Marumo T., Kim S. R., Monna T., Kobayashi K., Tango T., Cancer, 76, 743-749 (1995).

10) Bartold P. M., Haynes D. R., J. Periodontal Res., 26, 339-345 (1991).

11) Tamura M., Tokuda M., Nagaoka S., Takada H., Infect. Immun., 60, 4932-4937 (1992).

12) Sismey-Durrant H. J., Hopps R. M., Oral Microbiol. Immunol., 6, 378-380 (1991).

13) Ara T., Kurata K., Hirai K., Uchihashi T., Uematsu T., Imamura Y., Furusawa K., Kurihara S., Wang P. L., J. Periodontal Res. (in press) (doi:10.1111/j.1600-0765.2007.01041.x).

14) Wang P. L., Sato K., Oido M., Fujii T., Kowashi Y., Shinohara M., Ohura K., Tani H., Kuboki Y., Arch. Oral Biol., 43, 687-694 (1998).

15) Tamura T., Udagawa N., Takahashi N., Miyaura C., Tanaka S., Yamada Y., Koishihara Y., Ohsugi Y., Kumaki K., Taga T., Kishimoto T., Suda T., Proc. Natl. Acad. Sci. U.S.A., 90, 11924-11928 (1993).

16) Okada H., Murakami S., Crit. Rev. Oral Biol. Med., 9, 248-266 (1998).

17) Liu Z. L., Tanaka S., Horigome H., Hirano T., Oka K., Biol. Pharm. Bull., 25, 37-41 (2002).

18) Woo K. J., Lim J. H., Suh S. I., Kwon Y. K., Shin S. W., Kim S. C., Choi Y. H., Park J. W., Kwon T. K., Immunobiology, 211, 359-368 (2006).

19) Chen Y. C., Shen S. C., Chen L. G., Lee T. J., Yang L. L., Biochem. Pharmacol., 61, 1417-1427 (2001).

20) Chi Y. S., Kim H. P., Prostaglandins, Leukotrienes Essent. Fatty Acids, 72, 59-66 (2005).

21) Bermejo Benito P., Abad Martínez M. J., Silván Sen A. M., Sanz Gómez A., Fernández Matellano L., Sánchez Contreras S., Díaz Lanza A. M., Life Sci., 63, 1147-1156 (1998).

22) Georganas C., Liu H., Perlman H., Hoffmann A., Thimmapaya B., Pope R. M., J. Immunol., 165, 7199-7206 (2000).

23) Offenbacher S., Farr D. H., Goodson J. M., J. Clin. Periodontol., 8, 359-367 (1981).

24) Abramson M. M., Wolff L. F., Offenbacher S., Aeppli D. M., Hardie N. D., Friedman H. M., J. Periodontal Res., 27, 539-543 (1992).

25) Jeffcoat M. K., Reddy M. S., Haigh S., Buchanan W., Doyle M. J., Meredith M. P., Nelson S. L., Goodale M. B., Wehmeyer K. R., J. Periodontol., 66, 329-338 (1995).

26) Kearney P. M., Baigent C., Godwin J., Halls H., Emberson J. R., Patrono C., Brit. Med. J., 332, 1302-1308 (2006).

27) Andersohn F., Schade R., Suissa S., Garbe E., Stroke, 37, 1725-1730 (2006). 